\title{
Nationwide Analysis of Mortality Rates and Related Surgical Procedures in Hearing Disability Patients in South Korea
}

\author{
Hye Min Han, Ji Won Kwak, Hyeon Geun Kim, Hoyoung Lee, Young-Chan Kim, \\ Euyhyun Park, Hak Hyun Jung, and Gi Jung Im \\ Department of Otorhinolaryngology, Korea University College of Medicine, Seoul, Korea
}

Received July 7,2020

Revised September 7, 2020

Accepted September 21, 2020

\author{
Address for correspondence \\ Gi Jung Im, MD, PhD \\ Department of Otorhinolaryngology, \\ Korea University \\ College of Medicine, \\ 73 Goryeodae-ro, Seongbuk-gu, \\ Seoul 02841, Korea \\ Tel $+82-2-920-5486$ \\ Fax +82-2-925-5233 \\ E-mail logopas@korea.ac.kr
}

\begin{abstract}
Background and Objectives: Hearing loss $(\mathrm{HL})$ and its repercussions are major problems in today's society. There are limited data on the relationship between degree of $\mathrm{HL}$ and otologic disorders. The aim of this study is to estimate mortality rates, rates of sudden idiopathic HL and related otologic surgical procedures in hearing disability patients in South Korea. Subjects and Methods: Retrospective medical data for 160,205 patients with hearing disability was extracted. Mortality rates, rates of sudden idiopathic $\mathrm{HL}$ and related otologic surgical procedures were compared with a normal control group consisting of 865,475 people; approximately 5 times the number of hearing disability patients. Results: According to the Korean National Disability Registry (NDR), $0.458 \%$ of the population in South Korea suffered from hearing disability in 2015. Higher rates of mortality and sudden idiopathic $\mathrm{HL}$ were reported in hearing disability patients, increasing up to a maximum of 1.594 times and 1,039.695 times, respectively, compared to the normal control group. Mastoidectomy surgery was 2.5 times more frequently performed and pressure equalizing (PE) tube insertion was about 15 times more frequently performed in hearing disability patients. Conclusions: Hearing disability is related to higher risks of mortality, sudden idiopathic $\mathrm{HL}$ and otologic surgical procedures, including mastoidectomy and PE tubing.

J Audiol Otol 2020;24(4):204-209

KEY WORDS: Hearing loss · Persons with hearing impairments · Mortality Sudden hearing loss $\cdot$ Mastoidectomy $\cdot$ Middle ear ventilation . Republic of Korea.
\end{abstract}

\section{Introduction}

As the South Korean population is rapidly progressing towards an aged society, hearing loss (HL), a relatively common condition amongst the elderly population, and its repercussions are becoming major issues for the whole country. HL can be defined as the loss of hearing in one or both ears and can be caused by various reasons.

Many previous studies on HL and its consequences have been conducted. HL causes communication disorders [1], affecting a person's social and psychological well-being, and is a well-known risk factor of dementia [2] and depression [3].

This is an Open Access article distributed under the terms of the Creative Commons Attribution Non-Commercial License (https://creativecommons.org/licenses/by-nc/4.0/) which permits unrestricted non-commercial use, distribution, and reproduction in any medium, provided the original work is properly cited.
HL was also identified as a risk factor for various diseases related to mortality, including ischemic stroke [4] and cardiovascular disease [5]. While many papers validated the relationship between HL and mortality (Table 1) [5-9], there were only a few that discussed whether the severity of HL affects mortality rates. We were also unable to find any papers on whether specific diseases such as chronic otitis media, a fairly common treatable factor of $\mathrm{HL}$, are related to various degrees of hearing.

In this study, we aim to find out how hearing disability affects mortality with a nationwide population-based database in South Korea. We analyzed those registered as hearing disability patients in the National Disability Registry (NDR) and compared them to a normal control group. While doing so, we also aimed to find out whether specific otologic diseases were also affected, and whether these results differ according to various degrees of $\mathrm{HL}$. 
Table 1. Analysis of hearing loss $(\mathrm{HL})$ and mortality rates from previous studies

\begin{tabular}{|c|c|c|c|}
\hline Study & Country & HL definition & Mortality rate in $\mathrm{HL}$ patients \\
\hline Our study & South Korea & $\begin{array}{l}\text { Pure tone average } \geq 90 \mathrm{~dB} \text { in both ears } \\
\text { and speech disorder }\end{array}$ & $\begin{array}{l}1.594 \text { times higher compared to the } \\
\text { normal control group }\end{array}$ \\
\hline Contrera, et al. [6] & United States & $\begin{array}{l}\mathrm{No} H \mathrm{H},<25 \mathrm{~dB} \text {; mild } \mathrm{HI} \geq 25 \mathrm{~dB} \text { but }<40 \mathrm{~dB} \text {; } \\
\text { moderate or more severe } \mathrm{HI}, \geq 40 \mathrm{~dB}\end{array}$ & $\begin{array}{l}54 \% \text { increased risk of mortality in } \\
\text { moderate or more severe } \mathrm{HI}, 27 \% \\
\text { increased risk of mortality in mild } \mathrm{HI}\end{array}$ \\
\hline Genther, et al. [7] & United States & Pure tone average $>25 \mathrm{~dB}$ in the better ear & $20 \%$ increased mortality risk \\
\hline Lin, et al. [8] & United States & Self-perceived & $\begin{array}{l}\text { 5-year mortality rate: } 3.0 \% \text { in excellent/ } \\
\text { good hearing vs. } 19.5 \% \text { in a lot of trouble } \\
\text { hearing vs. } 17.8 \% \text { in deaf }\end{array}$ \\
\hline Fisher, et al. [9] & Iceland & $\begin{array}{l}>35 \mathrm{~dB} \text { for the pure tone average of } 0.5 \text {, } \\
1,2, \text { and } 4 \mathrm{kHz} \text { in the better ear }\end{array}$ & HR 1.70 (1.27-2.27) for CVD mortality \\
\hline Karpa, et al. [5] & Australia & Pure tone average $>25 \mathrm{~dB}$ in the better ear & $\begin{array}{l}\text { HR } 1.36 \text { (1.08-1.84) for cardiovascular } \\
\text { mortality, HR } 1.39(1.11-1.79) \text { for all-cause } \\
\text { mortality }\end{array}$ \\
\hline
\end{tabular}

In our study, mortality rates increased linearly as HL worsened, as proven in many previous studies. HI: hearing impairment, HR: hazard ratio, CVD: cardiovascular disease

\section{Subjects and Methods}

\section{Subjects}

Retrospective medical data from the year 2015 was extracted from the Korean National Health Insurance Service (KNHIS) and NDR. The KNHIS and NDR are both organizations run by the South Korean government in which all South Korean nationals and their medical data are registered. Patients were identified and classified based on their international classification of diseases (ICD)-10 code (Sudden idiopathic HL: H91.2, Cholesteatoma: H71). Treatment procedures received were based on practice codes proposed by the Korean Health Insurance Review and Assessment Service (KHIRA). Any identifiable personal data were excluded and thus, the KNHIS approved the study without informed consent from every individual. This study was approved by the Korea University Anam Hospital institutional review board (IRB No. 2019AN0507).

In order to be registered as having hearing disability in the NDR and receive relevant financial support, one must undergo at least three tests of pure tone audiometry (PTA) exams within a 2-7-day interval. The PTA results must then be confirmed using an auditory brainstem response (ABR) or auditory steady-state response (ASSR). Air-conduction thresholds at $0.5,1,2$ and $4 \mathrm{kHz}$ from each person's PTA exam were used to assess hearing ability using the following equation: $(0.5 \mathrm{kHz}+1 \mathrm{kHz} \times 2+2 \mathrm{kHz} \times 2+4 \mathrm{kHz}) / 6$. Hearing disability patients were then accordingly categorized into 6 groups, as classified by the Korean NDR. Hearing disability grade group 1 patients had hearing $\geq 90$ decibels $(\mathrm{dB})$ in both ears with some form of speech disorder defined by the Korean NDR.
Hearing disability grade group 2 patients had hearing $\geq 90 \mathrm{~dB}$ in both ears, but without any speech problems. Hearing disability grade groups 3,4 , and 5 consisted of patients with hearing $\geq 80, \geq 70$, and $\geq 60 \mathrm{~dB}$ in both ears, respectively. Hearing disability grade group 6 patients had hearing $\geq 80 \mathrm{~dB}$ in the worse ear and hearing $\geq 40 \mathrm{~dB}$ in the better ear. The KNHIS reviews the examination results with the help of a medical professional specializing in otology on whether the person is a suitable candidate for these benefits. Therefore, it is reasonable to say that analyzing the NDR data is a suitable means for examining medical trends and data in hearing disability patients.

A total of 237,272 (0.458\%) patients were registered in the Korean NDR as having hearing disability in 2015. Those with cancer, myocardial infarction, stroke, and insufficient information $(n=77,067)$ were excluded and 160,205 patients were ultimately enrolled in the study. A control group consisting of 865,475 people, approximately 5 times the number of HL patients involved in the study, were selected amongst those who are registered as not having hearing disability for comparison (Fig. 1A).

\section{Statistics}

The hazard ratios (HRs) and 95\% confidence intervals (CIs) for each outcome were analyzed using Cox proportional hazard models, using the normal control group as a reference group. Statistical analysis was carried out using the SAS STAT software version 9.3 (SAS Institute, Cary, NC, USA). All calculations were adjusted for age, sex, smoking, alcohol consumption, regular exercise, hypertension, dyslipidemia, and diabetes mellitus. 


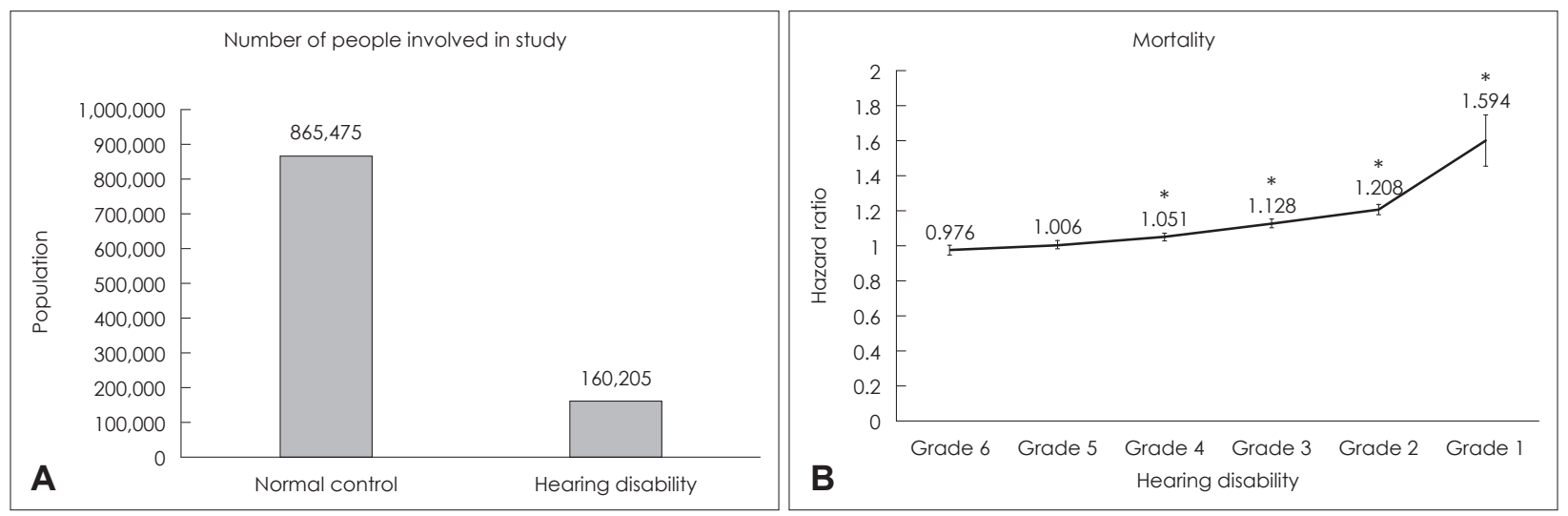

Fig. 1. Study design and mortality rates in hearing disability grade groups compared to normal control group. (A) A total of 160,205 patients registered in the Korean National Health Insurance Service (KNHIS) and South Korean National Disability Registry (NDR) as having hearing disability in 2015 were enrolled in this study. A control group $(n=865,475)$ consisting of 5 times the number of hearing disability patients were selected for comparison after adjustment for the following factors: age, sex, smoking, alcohol consumption, regular exercise, hypertension, dyslipidemia, and diabetes mellitus. (B) Mortality rates in each hearing disability grade group compared to the normal control group. A linear relationship was observed between hearing loss (HL) and mortality rate; mortality risk increased as hearing function worsened. Rates were highest in the hearing disability grade 1 group at 1.594 times higher compared to the control group. Grade 1: $\mathrm{HL} \geq 90 \mathrm{~dB}$ in both ears with speech disorder, Grade 2: $\mathrm{HL} \geq 90 \mathrm{~dB}$ in both ears, Grade 3: $\mathrm{HL} \geq 80 \mathrm{~dB}$ in both ears, Grade 4: $\mathrm{HL} \geq 70 \mathrm{~dB}$ in both ears, Grade 5: $\mathrm{HL} \geq 60 \mathrm{~dB}$ in both ears, Grade 6: $\mathrm{HL} \geq 80 \mathrm{~dB}$ in the worse ear and $\mathrm{HL} \geq 40 \mathrm{~dB} H \mathrm{HL}$ in the better ear. *statistically significant.

\section{Results}

\section{General demographic figures of South Korea}

The total South Korean population has been increasing gradually over the past several years, from 48 million in 2006 to 51 million in 2015. South Korea's gross national income (GNI) per capita also shows a general increase in rates. Figures dropped briefly in 2009 to 21 thousand, but recovered over time to reach 27 thousand in 2015, ranking 42th globally. Since 2011, the total South Korean population with hearing disability has been slowly declining. Although a male predominant pattern was observed in the hearing disability population, a similar decreasing pattern was seen in both genders (Fig. 2).

Mortality rates are higher in those with worse hearing functions

Mortality HR were 0.976 (95\% CI: 0.95-1.003), 1.006 (95\% CI: $0.983-1.028), 1.051$ (95\% CI: 1.029-1.073), 1.128 (95\% CI: $1.103-1.154), 1.208$ (95\% CI: $1.18-1.237)$ and 1.594 (95\% CI: $1.453-1.747)$ in hearing disability grade groups 6 , $5,4,3,2$ and 1, respectively. Results for hearing disability grade groups 5 and 6 were not statistically significant. In hearing disability grade groups 1, 2, 3 and 4 however, mortality rates increased as hearing function worsens (Fig. 1B).

\section{Sudden idiopathic $\mathrm{HL}$}

Sudden idiopathic HL HR were 145.63 (95\% CI: 92.356229.633), 233.714 (95\% CI: 150.366-363.261), 418.468 (95\%
CI: $274.587-637.742), 754.747$ (95\% CI: 500.739-1,137.604), 777.312 (95\% CI: 518.706-1,164.847) and 1,039.695 (95\% CI: 675.206-1,600.943) in hearing disability grade groups 6, $5,4,3,2$ and 1, respectively. Rates were significantly higher in all hearing disability grade group patients compared to the normal control group (Fig. 3).

\section{Cholesteatoma}

Cholesteatoma HR were 2.745 (95\% CI: 2.593-2.906), 2.499 (95\% CI: $2.356-2.65), 2.369$ (95\% CI: $2.235-2.511)$, 2.028 (95\% CI: $1.901-2.163), 1.505$ (95\% CI: $1.414-1.603)$ and 1.267 (95\% CI: $0.991-1.619)$ in hearing disability grade groups 6, 5, 4, 3, 2 and 1, respectively. Among patients with hearing disability, cholesteatoma was more prevalent in patients with milder degrees of HL (Fig. 4).

\section{Mastoidectomy and pressure equalizing tubing}

Mastoidectomy HR were 2.509 (95\% CI: 2.215-2.843), 1.834 (95\% CI: $1.597-2.106), 1.668$ (95\% CI: $1.449-1.92)$, 1.24 (95\% CI: $1.046-1.471), 0.754$ (95\% CI: $0.624-0.911)$ and 0.6 (95\% CI: $0.269-1.336)$ in hearing disability grade groups $6,5,4,3,2$ and 1, respectively. Pressure equalizing (PE) tubing HR were 14.143 (95\% CI: 13.13-15.234), 9.259 (95\% CI: 8.495-10.092), 10.881 (95\% CI: 10.055-11.775), 9.722 (95\% CI: 8.939-10.575), 5.801 (95\% CI: 5.313-6.335) and 3.836 (95\% CI: 2.69-5.47) in hearing disability grade groups 6, 5, 4, 3, 2 and 1, respectively. Both types of surgeries were also more commonly performed among those with milder degrees of HL (Fig. 5). 

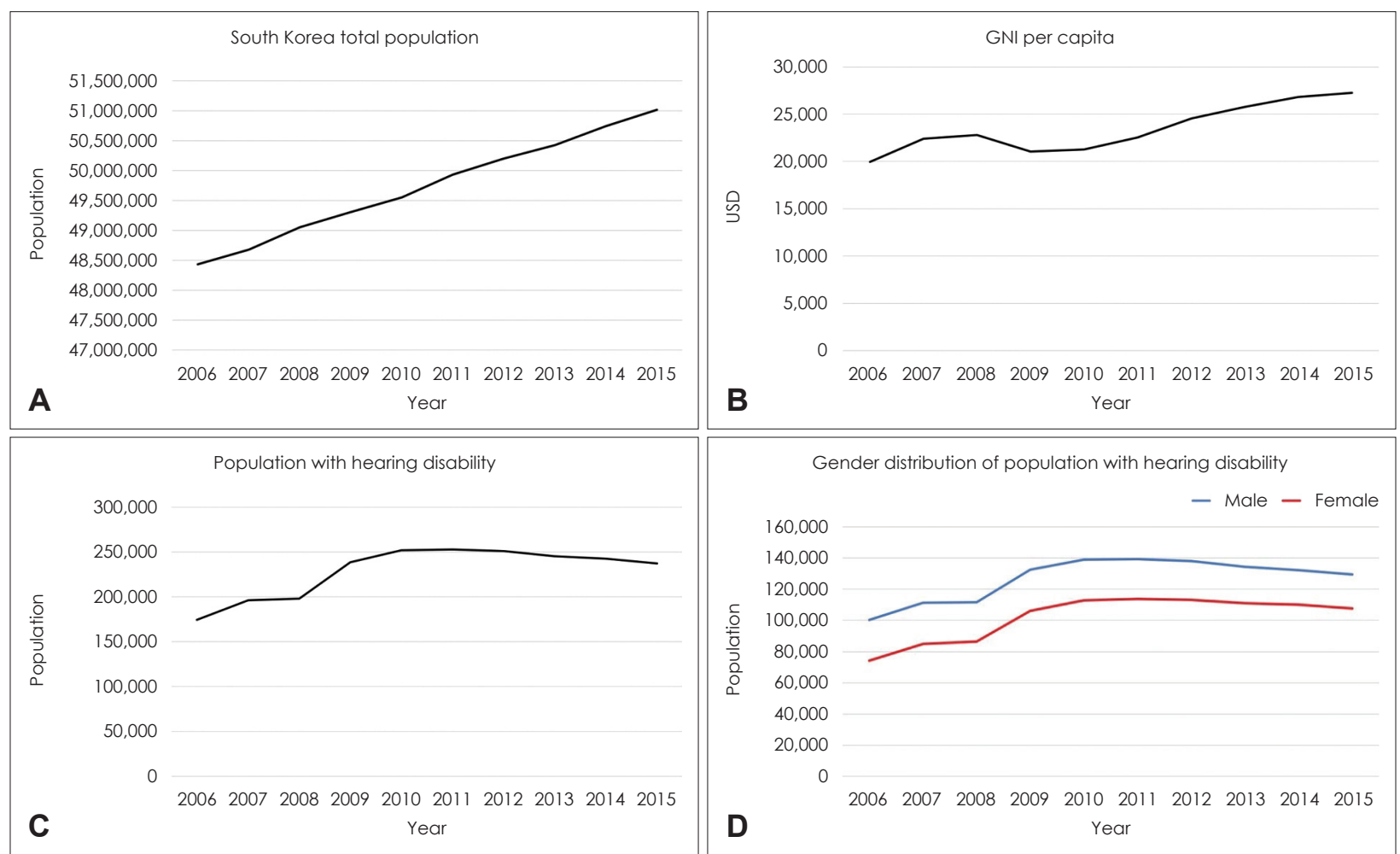

Fig. 2. General statistical figures in South Korea (2006-2015). (A) South Korean population increases from 2006 to 2015 , from 48 million to 51 million. (B) South Korean gross national income (GNI) per capita generally increases over time. Figures dropped briefly in 2009 to 21 thousand, probably due to the effects of the global financial crisis in 2007-2008, but rates recovered over time and reached 27 thousand in 2015, ranking 42th globally. (C) South Korean population with hearing disability increases over time and reaches a peak in 2011 at 253 thousand. From then on, figures start to slowly decline. In 2015, the population with hearing disability in South Korea was 237 thousand. (D) Gender distribution of hearing disability population in South Korea. Hearing disability rates were significantly higher in males than females. Figures in both genders show similar trends, reaching a peak in 2011 and gradually declining afterwards. USD: US dollar.

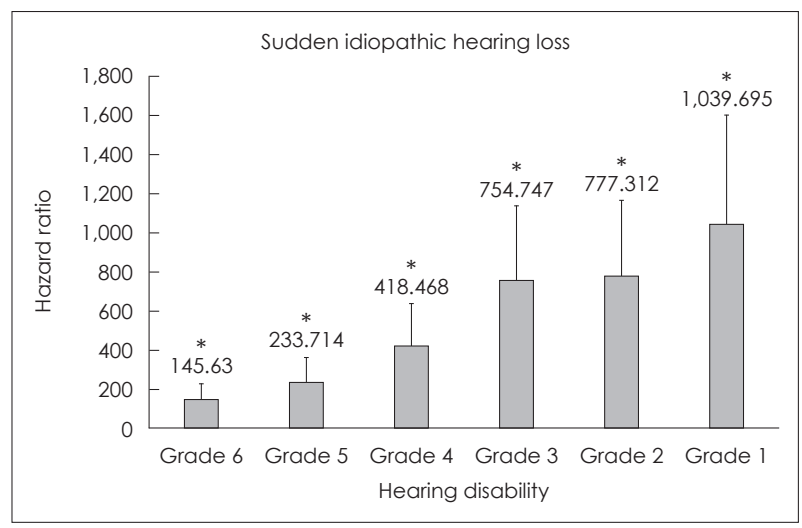

Fig. 3. Prevalence of sudden idiopathic hearing loss $(\mathrm{HL})$ in each hearing disability grade group compared to the normal control group. Sudden idiopathic HL rates were significantly higher in all hearing disability grade groups compared to the normal control group. A linear relationship between hearing disability grade and sudden idiopathic $\mathrm{HL}$ was observed. Rates increased from 145.63 times in the hearing disability grade 6 group to $1,039.695$ times in the hearing disability grade 1 group. Grade $1: \mathrm{HL} \geq 90 \mathrm{~dB}$ in both ears with speech disorder, Grade 2 : $\mathrm{HL} \geq 90 \mathrm{~dB}$ in both ears, Grade 3: $\mathrm{HL} \geq 80 \mathrm{~dB}$ in both ears, Grade 4: $\mathrm{HL} \geq 70 \mathrm{~dB}$ in both ears, Grade 5: $\mathrm{HL} \geq 60 \mathrm{~dB}$ in both ears, Grade 6: $\mathrm{HL} \geq 80 \mathrm{~dB}$ in the worse ear and $\mathrm{HL} \geq 40 \mathrm{~dB} \mathrm{HL}$ in the better ear. *statistically significant.

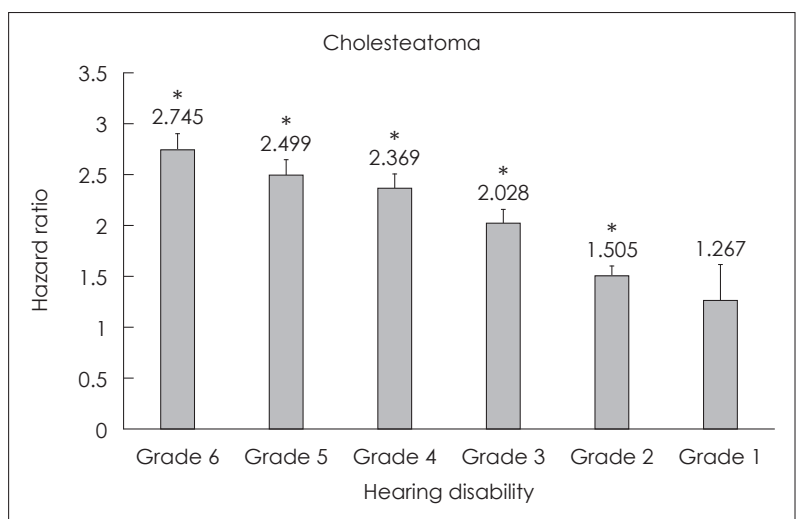

Fig. 4. Cholesteatoma rates in hearing disability grade groups compared to the normal control group. Prevalence of cholesteatoma was generally higher in all hearing disability grade groups than the normal control group. However, unlike the trend observed in the rate of sudden idiopathic hearing loss $(\mathrm{HL})$, the rate of cholesteatoma decreased as hearing function worsened. Cholesteatoma was more commonly observed in patients with milder degrees of $\mathrm{HL}$ among hearing disability patients. Rates were highest in the hearing disability grade 6 group, at 2.745 higher than the normal control group. Grade 1: $\mathrm{HL} \geq 90 \mathrm{~dB}$ in both ears with speech disorder, Grade 2: $\mathrm{HL} \geq 90 \mathrm{~dB}$ in both ears, Grade 3: $\mathrm{HL} \geq 80 \mathrm{~dB}$ in both ears, Grade $4: \mathrm{HL} \geq 70 \mathrm{~dB}$ in both ears, Grade 5: $\mathrm{HL} \geq 60 \mathrm{~dB}$ in both ears, Grade 6: $\mathrm{HL} \geq 80 \mathrm{~dB}$ in the worse ear and $\mathrm{HL} \geq 40 \mathrm{~dB} H \mathrm{H}$ in the better ear. "statistically significant. 

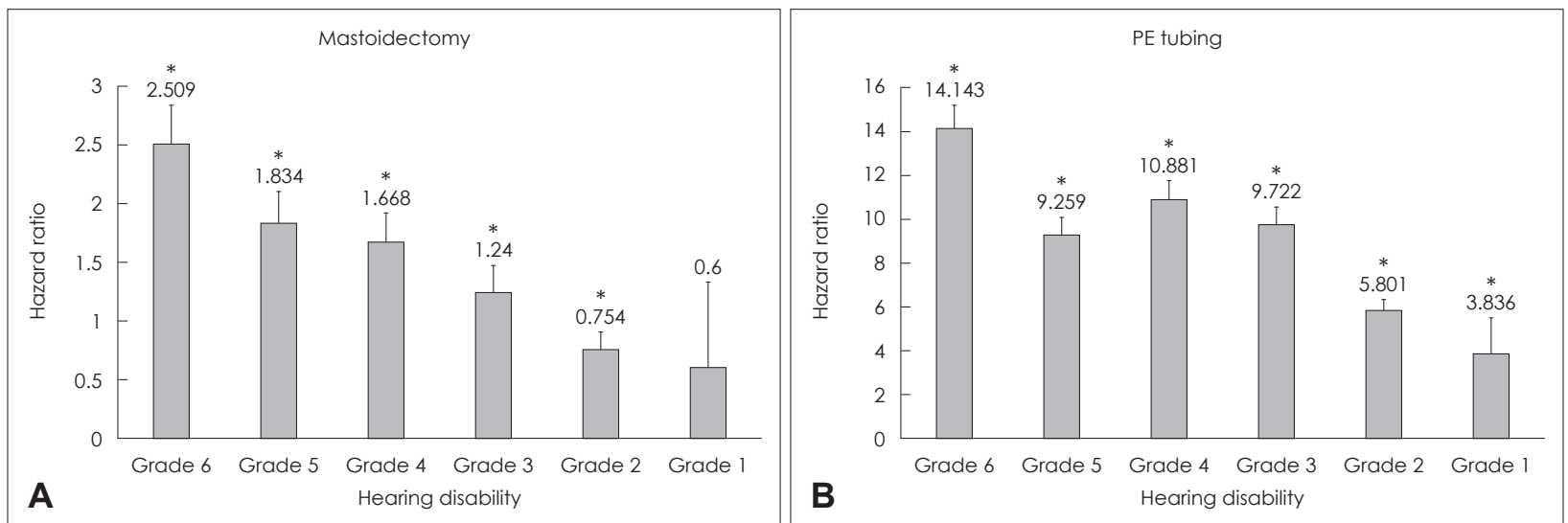

Fig. 5. Relative risk of performing Mastoidectomy and pressure equalizing (PE) tubing surgery in hearing disability patients compared to the normal control group. PE tubing was more frequently performed in all hearing disability grade groups compared to the normal control group. Mastoidectomy was more frequently performed in hearing disability grade groups $3,4,5$, and 6 compared to the normal control group. In general, rates of both procedures were higher in those with milder degrees of hearing loss (HL). (A) Mastoidectomy surgery was 2.509 times more frequently performed in the hearing disability grade group 6 patients than the normal control group. (B) PE tubing rates were highest in the hearing disability grade 6 group at 14.143 times higher than the normal control group. Grade 1: $\mathrm{HL} \geq 90$ $\mathrm{dB}$ in both ears with speech disorder, Grade 2: $\mathrm{HL} \geq 90 \mathrm{~dB}$ in both ears, Grade 3: $\mathrm{HL} \geq 80 \mathrm{~dB}$ in both ears, Grade 4: HL $\geq 70 \mathrm{~dB}$ in both ears, Grade 5: $\mathrm{HL} \geq 60 \mathrm{~dB}$ in both ears, Grade 6: $\mathrm{HL} \geq 80 \mathrm{~dB}$ in the worse ear and $\mathrm{HL} \geq 40 \mathrm{~dB} \mathrm{HL}$ in the better ear. *statistically significant.

\section{Discussion}

All South Korean nationals are registered in the KNHIS and all medical activities are recorded. This makes South Korea an ideal country for observing various medical trends through a nation-based population analysis. To our knowledge, this study is the first nationwide big data analysis conducted on HL and mortality in South Korea.

The population of South Korea increased along with economic growth over the past several years. The decreasing rate of HL implies that the medical trend of South Korea will resemble advanced countries. This indicates that South Korea's medical services, health quality and average standards of living are continuously improving. This has been a major contributing factor to South Korea rapidly becoming an aged society. As the population continues to age, $\mathrm{HL}$ and its repercussions are quickly becoming bigger concerns for the whole country, since the majority of HL patients are generally composed of those from older population groups [10].

Although the total South Korean population with hearing disability has been slowly decreasing since 2011, it still is a major health burden for the whole country. In 2015, 0.458\% of the whole South Korean population was documented as suffering from hearing disability. This study was conducted in order to find out how different severity of HL affects mortality and various otologic disorders using a nationwide population-based database in South Korea.

Our data demonstrates that mortality rates tend to increase as hearing function worsens. The hearing disability grade group 1 were at the highest risk of mortality, at 1.594 times higher compared to the normal control group. Our study results are comparable with previous findings that $\mathrm{HL}$ is associated with higher rates of mortality [5-9]. Hearing function is crucial in detecting and protecting oneself from dangerous situations. A study on accidental injuries in self-reported hearing difficulty patients was conducted in the United States, reporting an odds ratio of 1.9 in those with a lot of trouble hearing [11]. HL patients are also more likely to experience psychiatric disorders, including depression, which may lead to suicidal behavior. Not many literatures to date have studied suicide rates in deaf individuals. However, higher rates of suicide ideation and attempts were reported in deaf and hard-of-hearing college students [12]. Further studies on the issue may clarify the reason why mortality rates are higher in those with hearing disabilities.

Hearing disability was associated with a significantly higher rate of sudden idiopathic HL. Although spontaneous recovery is reported in the majority of patients with sudden idiopathic HL, symptoms may persist in many cases. Recovery from sudden idiopathic HL was reported as $59 \%$ in a previous study and profound HL was identified as a negative prognostic factor [13]. Patients with worse hearing functions are less likely to recover from sudden idiopathic HL, leading to higher rates of sudden idiopathic HL rates in those with worse hearing functions.

While sudden idiopathic HL was more prevalent in patients with worse degrees of HL, cholesteatoma was more prevalent in patients with milder degrees of HL; worse hearing function did not necessarily indicate a history of cholesteatoma. The expansile and destructive nature of cholesteatoma 
may lead to erosion of the ossicles and tympanic membrane, leading to HL [14]. HL may also be a symptom of labyrinthine fistula, another possible complication of cholesteatoma.

Similarly, rates of mastoidectomy surgery and PE tubing were also higher in patients with milder degrees of HL. We can assume from our data that diseases requiring mastoidectomy or PE tubing surgery, such as otitis media or cholesteatoma, rarely cause deafness; they are more likely to cause milder degrees of HL. In those with worse hearing functions, such as hearing disability grade groups 1,2 or 3 , the underlying cause is probably due to sensorineural HL, rather than inflammatory diseases.

The limitation of this study is that because the data used in this study is based on disease code, so those who have never sought medical treatment may not have been represented in our data. However, individuals listed as hearing disability patients in South Korea are thoroughly checked on hearing status and medical comorbidities. Data concerning these patients are extremely accurate and reliable. Another possible limitation is due to this study being based on a big-data analysis; several factors were not taken into account due to limited information. One was HL duration, a very important factor which could affect mortality and otologic surgeries. However, all patients registered as hearing disability patients in the Korean NDR must have persistent HL despite at least 6 months of sufficient treatment. Therefore, we can conclude that only patients with HL lasting longer than 6 months were included in this study and short-term HL patients were excluded. The other was hearing rehabilitation such as hearing aid or cochlear implant. Information on whether patients actually used these devices cannot be obtained from the system.

In conclusion, our data demonstrate that hearing disability is related to higher risks of mortality, sudden idiopathic $\mathrm{HL}$ and otologic surgical procedures, including mastoidectomy and PE tubing. Prevention of HL and appropriate management of related conditions may contribute to further improving life standards and reducing mortality.

\section{Acknowledgments}

This work was supported by the National Research Grant funded by the Korea Health Industry Development Institute (R1606512, R1621963, R1429733) and Korea University Research Fund (K1912851, K1813271, K2005001, K2008511). These funding sources provided only financial support and played no specific scientific role in this study.

\section{Conflicts of interest}

The authors have no financial conflicts of interest.

\section{Author Contributions}

Conceptualization: Gi Jung Im. Data curation: Hye Min Han and Young-Chan Kim. Investigation: Hye Min Han and Hoyoung Lee. Methodology: Hye Min Han and Ji Won Kwak. Project administra- tion: Gi Jung Im. Resources: Gi Jung Im. Supervision: Euyhyun Park and Hak Hyun Jung. Validation: Gi Jung Im. Visualization: Hye Min Han and Hyeon Geun Kim. Writing - original draft: Hye Min Han. Writing — review \& editing: Hye Min Han and Gi Jung Im. Approval of final manuscript: all authors.

\section{ORCID iDs}

Hye Min Han

Ji Won Kwak

Hyeon Geun Kim

Hoyoung Lee

Young-Chan Kim

Euyhyun Park

Hak Hyun Jung

Gi Jung Im https://orcid.org/0000-0002-5612-1261

https://orcid.org/0000-0002-1907-0178

https://orcid.org/0000-0002-0174-279X

https://orcid.org/0000-0002-8200-0033

https://orcid.org/0000-0001-9510-1354

https://orcid.org/0000-0003-4373-6942

https://orcid.org/0000-0002-4402-1132

https://orcid.org/0000-0002-9457-4253

\section{REFERENCES}

1) Ciorba A, Bianchini C, Pelucchi S, Pastore A. The impact of hearing loss on the quality of life of elderly adults. Clin Interv Aging 2012;7:159-63.

2) Lin FR, Metter EJ, O'Brien RJ, Resnick SM, Zonderman AB, Ferrucci L. Hearing loss and incident dementia. Arch Neurol 2011;68: 214-20.

3) Cosh S, Carriere I, Delcourt C, Helmer C, Consortium TS. A dimensional approach to understanding the relationship between self-reported hearing loss and depression over 12 years: the Three-City study. Aging Ment Health 2020 Mar 13 [Epub]. https://doi.org/10.1 080/13607863.2020.1727845.

4) Kim SY, Lim JS, Sim S, Choi HG. Sudden sensorineural hearing loss predicts ischemic stroke: a longitudinal follow-up study. Otol Neurotol 2018;39:964-9.

5) Karpa MJ, Gopinath B, Beath K, Rochtchina E, Cumming RG, Wang JJ, et al. Associations between hearing impairment and mortality risk in older persons: the Blue Mountains Hearing Study. Ann Epidemiol 2010;20:452-9.

6) Contrera KJ, Betz J, Genther DJ, Lin FR. Association of hearing impairment and mortality in the national health and nutrition examination survey. JAMA Otolaryngol Head Neck Surg 2015;141:944-6.

7) Genther DJ, Betz J, Pratt S, Kritchevsky SB, Martin KR, Harris $\mathrm{TB}$, et al. Association of hearing impairment and mortality in older adults. J Gerontol A Biol Sci Med Sci 2015;70:85-90.

8) Lin HW, Mahboubi H, Bhattacharyya N. Hearing difficulty and risk of mortality. Ann Otol Rhinol Laryngol 2019;128:614-8.

9) Fisher D, Li CM, Chiu MS, Themann CL, Petersen H, Jónasson F, et al. Impairments in hearing and vision impact on mortality in older people: the AGES-Reykjavik Study. Age Ageing 2014;43:69-76.

10) Im GJ, Ahn JH, Lee JH, Han KD, Lee SH, Kim JS, et al. Prevalence of severe-profound hearing loss in South Korea: a nationwide population-based study to analyse a 10-year trend (2006-2015). Sci Rep 2018;8:9940.

11) Lin HW, Mahboubi H, Bhattacharyya N. Self-reported hearing difficulty and risk of accidental injury in US adults, 2007 to 2015. JAMA Otolaryngol Head Neck Surg 2018;144:413-7.

12) Fox ML, James TG, Barnett SL. Suicidal behaviors and help-seeking attitudes among deaf and hard-of-hearing college students. Suicide Life Threat Behav 2020;50:387-96.

13) Edizer DT, Çelebi Ö, Hamit B, Baki A, Yiğit Ö. Recovery of idiopathic sudden sensorineural hearing loss. J Int Adv Otol 2015;11: $122-6$.

14) Holt JJ. Cholesteatoma and otosclerosis: two slowly progressive causes of hearing loss treatable through corrective surgery. Clin Med Res 2003;1:151-4. 